\title{
Investigations Concerning the Syntheses of TADDOL-Derived Secondary Amines and Their Use To Access Novel Chiral Organocatalysts
}

\author{
Katharina Gratzer, Mario Waser* \\ Institute of Organic Chemistry, Johannes Kepler University Linz, Altenbergerstraße 69, 4040 Linz, Austria \\ Fax +43(732)24688747; E-mail: Mario.waser@jku.at \\ Received: 06.09.2012; Accepted after revision: 24.09.2012
}

\begin{abstract}
A structurally carefully diversified library of novel TADDOL-derived chiral secondary amines was synthesized and investigated for their applicability to obtain new organocatalysts like chiral Lewis bases and chiral phase-transfer catalysts. The scope and limitations of the developed syntheses routes to access these catalysts as well their catalytic performance in different benchmark reactions were systematically investigated. The most powerful of the catalysts prepared was found to be highly useful for the phasetransfer catalyzed $\alpha$-alkylation of glycine Schiff base (high yields and up to $93 \%$ ee).
\end{abstract}

Key words: chiral pool, tartaric acid, asymmetric phase-transfer catalysis, Lewis base catalysis, asymmetric alkylation

The use of chiral small molecule organocatalysts to facilitate demanding stereoselective applications has attracted considerable interest over the last decade. ${ }^{1}$ One of the main prerequisites to develop this methodology further towards new, more generally applicable transformations with a broader reaction scope is the availability of powerful, easily obtainable and easily modified (fine-tuned) catalysts. We have recently started a project targeting the use of tartaric acid (1) or easily derived TADDOLs $\mathbf{2}$ to synthesize novel organocatalysts. Although TADDOLs are omnipresent as ligands in (transition) metal catalysis ${ }^{2}$ and tartaric acid is a versatile starting material for preparing important chiral compounds, ${ }^{3}$ the use of these easily available natural chiral pool-based starting materials to obtain asymmetric organocatalysts has so far been limited to a few (but often impressive) examples only. ${ }^{4-6}$ Whilst our initial investigations on the syntheses of TADDOLderived sulfonimides failed, ${ }^{7}$ we recently created a small library of novel TADDOL-derived $\mathrm{N}$-spiro quaternary ammonium salts 3 , which were found to be powerful phase-transfer catalysts (PTCs) for the stereoselective $\alpha$-alkylation of glycine Schiff bases. ${ }^{8}$ Encouraged by these promising initial results we have now undertaken systematic investigations concerning the syntheses and applicability of TADDOL-derived secondary amines $\mathbf{4}^{2,9}$ and $\mathbf{5}$ to synthesize a variety of structurally diverse novel chiral Lewis base catalysts ${ }^{10} 6-9$ and chiral phase-transfer catalysts ${ }^{11} \mathbf{3}, \mathbf{1 0}-\mathbf{1 2}$ (Scheme 1). The main focus in this work was therefore on the development of reliable and flexible synthetic strategies to achieve the key intermediates and a diverse library of catalysts and to elucidate the

SYNTHESIS 2012, 44, 3661-3670

Advanced online publication: 16.10 .2012

DOI: 10.1055/s-0032-1316804; Art ID: SS-2012-T0707-OP

(C) Georg Thieme Verlag Stuttgart · New York scope and limitations of these synthetic routes. In addition, the catalytic potential and the structure-activity relationship of the newly acquired catalysts in important benchmark reactions were investigated.
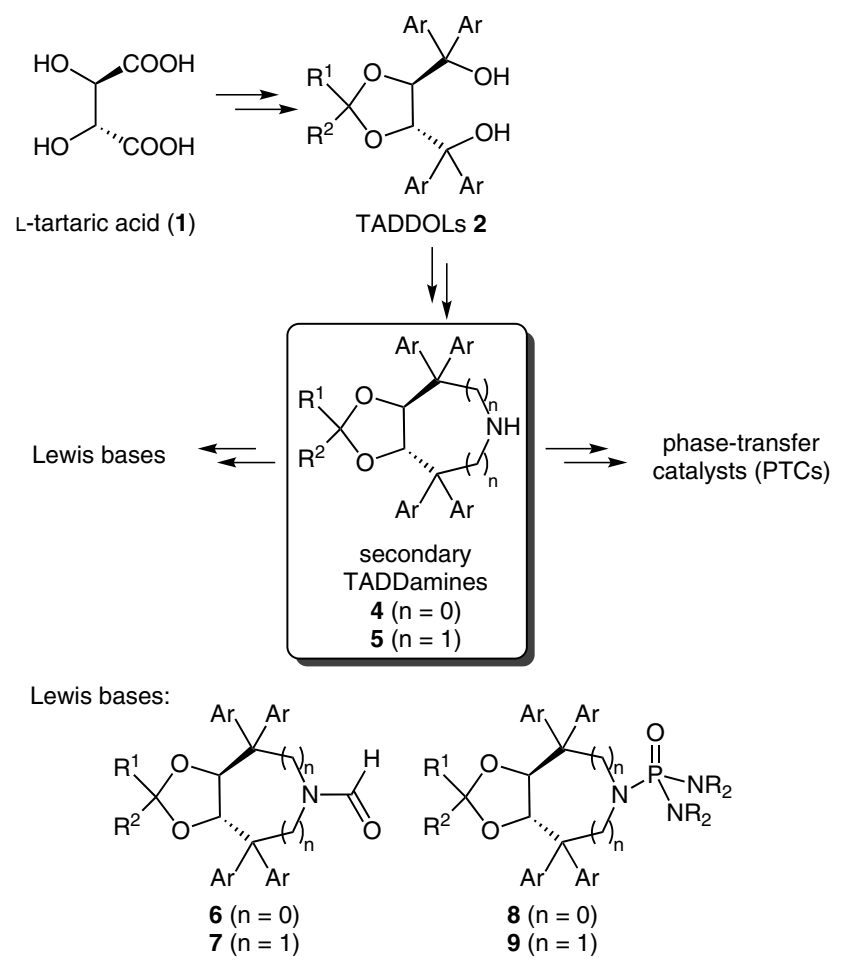

PTCs:
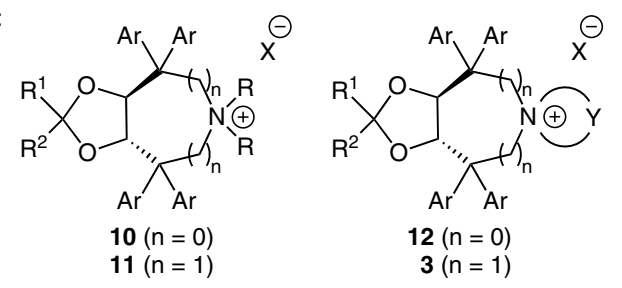

Scheme $\mathbf{1}$ Targeted key intermediate secondary amines $\mathbf{4}$ and $\mathbf{5}$ and envisaged asymmetric Lewis base and phase-transfer catalysts

\section{Pyrrolidine 4-Based Catalysts}

The syntheses of TADDOL derivatives have been carefully investigated and described in the past, especially by Seebach's group. ${ }^{2,9}$ Whereas different acetal/ketal groups and aryl substituents have to be introduced early in the synthesis of TADDOLs from tartaric acid (1), functionalizations of the hydroxyl groups are most commonly 
achieved via conversion of TADDOLs 2 into dichloro compounds 13, which can then be reacted with different nucleophiles. ${ }^{7,9}$ With respect to the syntheses of the pyrrolidine-containing catalysts the 'standard' TADDOL 2aa $\left(\mathrm{R}^{1}=\mathrm{R}^{2}=\mathrm{Me}, \mathrm{Ar}=\mathrm{Ph}\right)^{2,9}$ was first converted into the known azabicyclo[3.3.0]octane 4aa according to the published procedure. ${ }^{9 \mathrm{~b}}$ With this easily available compound in hand we first investigated the formation of the chiral formamide Lewis base 6aa. However, we were not able to obtain this compound as the secondary amine $\mathbf{4 a a}$ was found to be rather unreactive, even upon treatment with highly reactive acetic formic anhydride. During the course of our investigations we also became aware that the Seebach group experienced similar problems in modifying this compound and has also not been able to obtain 6aa. ${ }^{12}$ In addition, they also reported a surprisingly high instability of the ketal group of this compound under slightly acidic conditions, which fully corresponds to our experience with this highly strained trans-azabicyclo[3.3.0]octane. This enhanced instability of the normally rather stable acetonide moiety is also in line with recent results in our group obtained with an analogous transthiabicyclo[3.3.0] octane based TADDOL-derivative. ${ }^{7}$ Also treatment with several alkyl halides like 1,4-dibromobutane or bromobutane or methyl iodide under a variety of conditions never gave any quaternary ammonium salts 10aa or 12aa at all. The only transformation we observed was a very slow formation of traces of intermediate tertiary amines 14aa, but absolutely no quaternization could be achieved (Scheme 2). Moreover, the bicyclo[3.3.0] skeleton was also found to be unstable under harsher basic reaction conditions resulting in partial acetonide cleavage again. Accordingly, the use of the longknown secondary amine 4 aa to prepare novel chiral Lewis bases ${ }^{13}$ or PTCs is not only limited because of the reduced reactivity of the nitrogen, but also because of an increased instability of this compound. These observations also rationalize why this (on a first glance promising) compound has never really been used in any demanding applications.

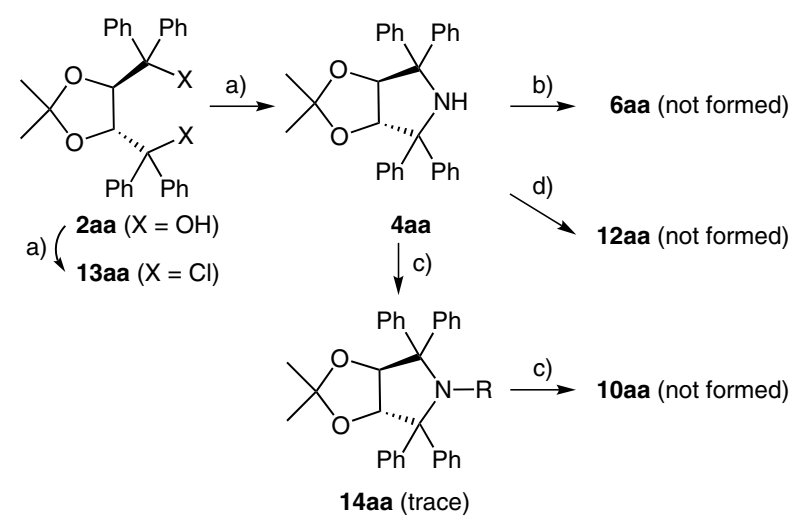

Scheme 2 Attempted syntheses of pyrrolidine 4aa based organocatalysts: Reagents and conditions: a) ref. 9b; b) acetic formic anhydride; c) different RX, different conditions; d) 1,4-dibromobutane, different conditions.

\section{Azepane 5-Based Phase-Transfer Catalysts}

We have recently succeeded in developing a four-step route to build a small library of azepane-based $C_{2}$-symmetric acetonide-containing $\mathrm{N}$-spiro catalysts 3a (based on the classical acetonide moiety with $\mathrm{R}^{1}=\mathrm{R}^{2}=\mathrm{Me}$ ) starting from known TADDOLs 2a (Scheme 3). ${ }^{8}$ Based on this initial success we have now undertaken systematic investigations concerning the scope and limitations of this route to synthesize new PTCs and also to employ the key intermediate 5 to realize novel chiral Lewis bases.



$\mathrm{Ar}=\mathrm{Ph}(\mathbf{a}) ; 4-t-\mathrm{BuC}_{6} \mathrm{H}_{4}(\mathbf{b}) ; 4-\mathrm{FC}_{6} \mathrm{H}_{4}(\mathbf{c}) ; 3-\mathrm{MeC}_{6} \mathrm{H}_{4}(\mathbf{d}) ; 3,5-\mathrm{Me}_{2} \mathrm{C}_{6} \mathrm{H}_{3}(\mathbf{e})$; $3-\mathrm{PhC}_{6} \mathrm{H}_{4}(\mathbf{f}) ; 4-\mathrm{PhC}_{6} \mathrm{H}_{4}(\mathbf{g})$

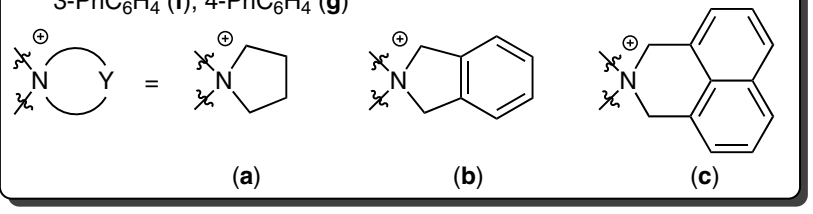

Scheme 3 Successful syntheses of a first library of $C_{2}$-symmetric acetonide-containing azepane-based PTCs 3a. ${ }^{8}$ Reagents and conditions: a) $\mathrm{SOCl}_{2}, \mathrm{Et}_{3} \mathrm{~N}, \mathrm{CH}_{2} \mathrm{Cl}_{2}, 25^{\circ} \mathrm{C}$; b) $\mathrm{TMSCN}, \mathrm{SnCl}_{4}, 25^{\circ} \mathrm{C}, 47-63 \%$ (over two steps); c) $\mathrm{LiAlH}_{4}$, mesitylene, reflux, 30-43\%; d) $\mathrm{Br}-\mathrm{Y}-\mathrm{Br}$, $\mathrm{K}_{2} \mathrm{CO}_{3}, \mathrm{MeCN}$, reflux, 49-69\%.

Initial route development was carried out using the parent TADDOL 2aa $\left(\mathrm{R}^{1}=\mathrm{R}^{2}=\mathrm{Me}, \mathrm{Ar}=\mathrm{Ph}\right)$. Surprisingly, elongation of the carbon chain of TADDOLs has so far not been systematically investigated. ${ }^{14}$ Reacting dichloro compound 13aa with TMSCN ( $>2.5$ equiv) in the presence of catalytic amounts of $\mathrm{SnCl}_{4}(25 \%)^{15}$ was rewarded with the formation of dinitrile 15aa in excellent yield on a multigram scale. Conversion into the secondary amine 5aa was found to be rather tricky as dinitrile 15aa turned out to be unreactive under a variety of different conditions. Attempted saponification failed even under very strong basic conditions (e.g., refluxing with $20 \% \mathrm{NaOH}$ resulted in the recovery of starting material accompanied with a partial decomposition). Attempted conversion into the corresponding dialdehyde upon treatment with DIBAL-H failed as 15aa was found to be unreactive under standard DIBAL-H reduction conditions or decomposed under more forcing conditions. Also other hydride donors like $\mathrm{NaBH}_{4}$ (also in combination with different additives), Red-Al, $\mathrm{LiBH}_{4}$, or $\mathrm{LiAlH}_{4}$ at room temperature in different ethereal solvents did not affect the cyano groups either. Interestingly, we discovered that refluxing heterogeneous mixtures of 15aa and excess $\mathrm{LiAlH}_{4}(20$ equiv) in high boiling aromatic solvents (mesitylene was found best) for 30-45 minutes gave access to amine 5aa in around 30-40\% isolated yield. HRMS studies of this re- 
action revealed the presence of amidine intermediates besides other unidentified by-products. These by-products were found to be nonpolar, highly fluorescent condensed aromatic compounds, containing no heterofunctionalities like the acetonide or cyano groups anymore. Attempts to increase the yields by using other solvents or different additives did not improve the outcome. Attempted heterogeneous hydrogenation was also not successful so far. ${ }^{16}$ However, having established a reliable route for the syntheses of the chiral secondary amine 5aa, the introduction of different aryl groups to modify the steric and electronic properties of this skeleton was focused next. As depicted in Scheme 3, a variety of different electron-neutral aryl substituents were introduced successfully during our initial investigations. Besides aryl groups with electronic properties similar to a phenyl group in amines $\mathbf{5 a}$ (and the corresponding catalysts), other aromatic residues bearing either electron-rich or electron-deficient groups also aroused our interest. Interestingly, a very strong difference in the reactivity of these compounds was observed. The presence of strong electron-donating groups like methoxy groups did not allow us to obtain the corresponding dichlorides 13a under a variety of different chlorination conditions, but instead different elimination and also Friedel-Crafts products were formed. ${ }^{17}$ On the other hand, strong electron-withdrawing substituents like trifluoromethyl groups did not give the dichlorides either, but instead the stable cyclic sulfites $\mathbf{1 6 a}$ were formed ${ }^{18}$ (Scheme 4). Unfortunately, neither changing the reaction conditions, nor using other chlorination agents like $\mathrm{PCl}_{5}$ or oxalyl chloride gave the targeted dichlorides 13a. Attempts to employ this sulfite further failed due to the high stability of this compound.

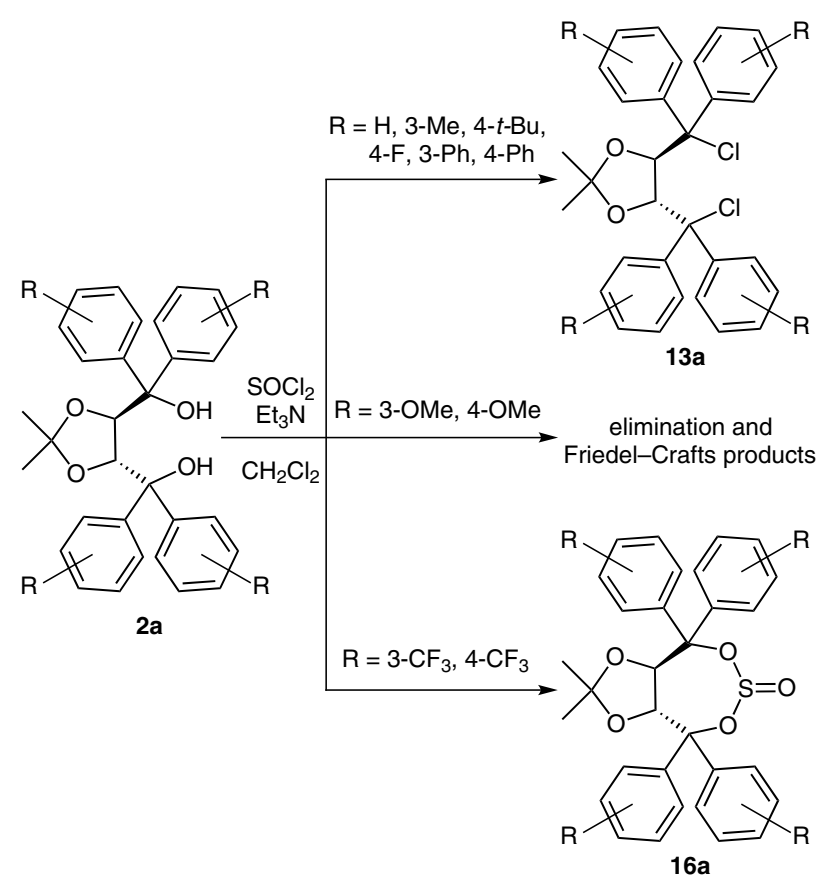

Scheme 4 Representative overview on the influence of the nature of different aryl groups on the chlorination reaction
Direct dicyanation of TADDOLs 2a with TMSCN in the presence of a Lewis acid worked with modest yields in the case of electron-neutral aromatic residues (e.g., 2aa was directly converted into $\mathbf{1 5 a}$ a in around $30 \%$ unoptimized yield) but again no conversion was observed in the case of electron poor aryl group containing TADDOLs. Accordingly, transformations of the benzylic position of the TADDOL-skeleton are highly dependent on the electronic properties of the aromatic substituents. Interestingly, whereas the corresponding naphth-2-yl-substituted dichloride was accessible, dicyanide formation was not possible in this case and just decomposition products were obtained. In contrast, the sterically demanding biphenylcontaining dicyanides $\mathbf{1 5}$ af and $\mathbf{1 5 a g}$ could be obtained in high yields. ${ }^{19}$ All the obtained acetonide-based dicyanides $\mathbf{1 5 a}$ could be converted into the secondary amines $\mathbf{5 a}$ in moderate yields (see Table 1).

The final quaternization step was first investigated targeting $\mathrm{N}$-spiro ammonium salts 3aa. In contrast to amine 4aa, the azabicyclo[5.3.0]decane 5aa $(\mathrm{Ar}=\mathrm{Ph})$ was found to be nucleophilic enough in the reaction with 1,4dibromobutane, giving the targeted ammonium bromide 3aaa (see Scheme $3 ; \mathrm{R}^{1}=\mathrm{R}^{2}=\mathrm{Me}, \mathrm{Ar}=\mathrm{Ph}, \mathrm{Y}=$ group a) in $60 \%$ isolated yield upon refluxing 5 aa with 4 equivalents dibromobutane ( $\mathrm{MeCN}, \mathrm{K}_{2} \mathrm{CO}_{3}$ ). Noteworthy, whereas only traces of the intermediate tertiary amine were observed, significant amounts of unreacted starting material 5aa could be reisolated. Similar results were obtained in the successful syntheses of catalysts 3aab $(\mathrm{Ar}=\mathrm{Ph}, \mathrm{Y}=$ group $\mathbf{b})$ and $3 \mathbf{a a c}(\mathrm{Ar}=\mathrm{Ph}, \mathrm{Y}=$ group $\mathbf{c})$. On the other hand, quaternization with 1,2-dibromoethane resulted in the formation of a very unstable aziridiniumbased ammonium salt that could not be employed further.

Attempting the quaternization with $\mathrm{BuBr}$ or $\mathrm{MeI}$ to prepare nonspiro ammonium salts $\mathbf{1 1}$, only the corresponding monoalkylated tertiary amines, but no quaternary ammonium compounds 11 could be obtained under a variety of different conditions. ${ }^{20}$ Accordingly, it seems that once the tertiary amine is formed, the final quaternization step only takes place intramolecularly. This might be rationalized by the fact that the lone pair of the tertiary nitrogen seems to be shielded towards an external electrophile by the bulky aryl substituents, making an intermolecular alkylation much more difficult than an intramolecular one. This explanation is also supported by additional molecular modeling studies.

Surprisingly, when attempts were made to carry out the quaternization with 1,5-dibromopentane or bis(2-bromoethyl) ether, only formation of the corresponding tertiary amines, and not even traces of the corresponding piperidine- or morpholine-based ammonium bromides could be observed. To elucidate this striking difference in the quaternization step additional calculations were carried out using different force fields and DFT methods to obtain the optimized structures for the pyrrolidinium-based catalyst 3aaa and the targeted piperidinium-based catalyst 3aad (Figure 1). A careful analysis revealed no striking differences between the parent skeletons of these two ammoni- 
um salts. Interestingly, in both cases two of the bulky phenyl groups are in an unfavored syn-pentane interaction (1,3-diaxial strain) with the newly introduced $\mathrm{CH}_{2}$ group adjacent to the spiro ammonium group. Having a closer look on the calculated tertiary amine intermediate it becomes obvious that the electrophile has to approach the nitrogen lone pair via a rather close channel between the phenyl groups. The calculated distances between the nearest carbon atoms of the phenyl rings is around $4.5 \AA$ and for the nearest protons around $3.7 \AA$. As the $\mathrm{S}_{\mathrm{N}} 2$-type 6ring formation is supposed to proceed via a sterically more demanding chair-type transition state with additional destabilizing 1,3-diaxial-type interactions between the large $\mathrm{N}$-substituents and the axial $\beta$-hydrogens, and whereas the 5-ring formation should proceed via a more planar transition state with a significantly lower transition state strain energy (resulting in a much faster cyclization reaction), ${ }^{21}$ it seems reasonable that our rather tight and crowded structure disfavors 6-ring formation significantly. Steric hindrance in the transition state was also accounted to be the main reason for the unsuccessful cyclization of substituted 1,4-dibromobutanes like $(R, R)$ or $(S, S)$-1,4-dibromo-2,3-dimethoxybutane where again absolutely no formation of quaternary ammonium salts could be observed.

Thus, and in contrast to analogous high-yielding transformations in the syntheses of the powerful Maruoka catalysts, ${ }^{22}$ the quaternization of amines $\mathbf{5}$ is a rather difficult
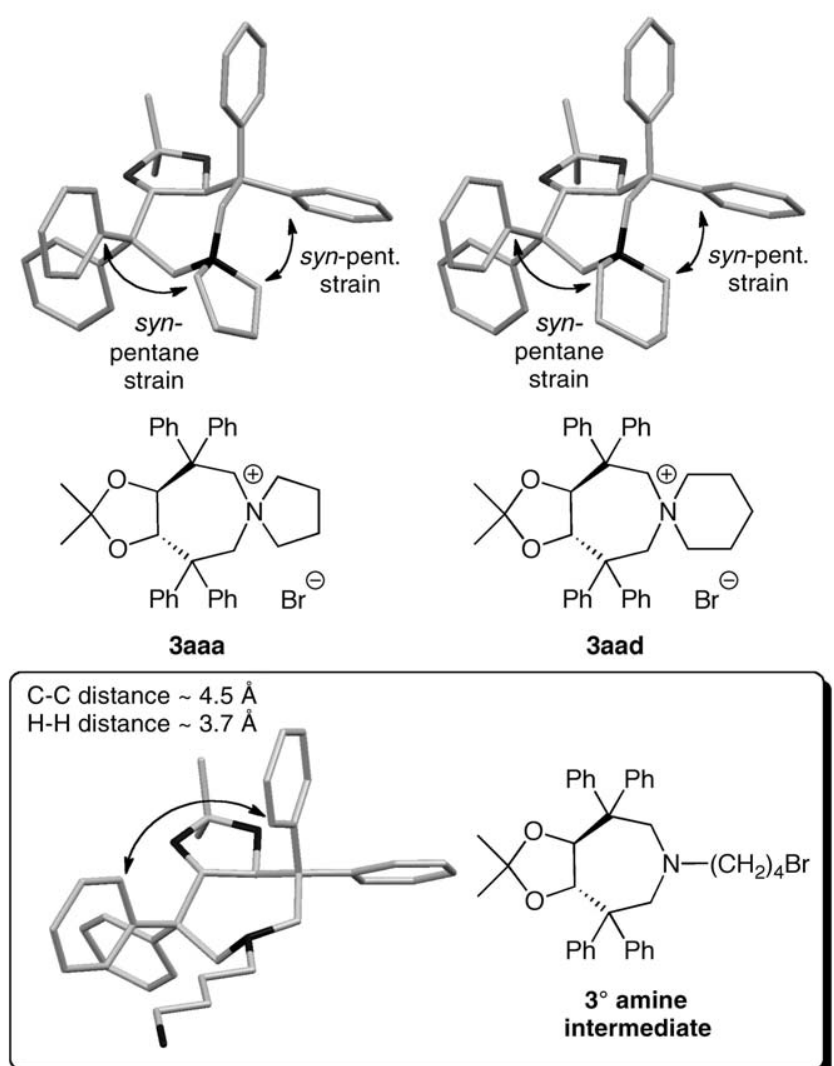

Figure 1 Comparison of the optimized structures of pyrrolidinium and piperidinium-based chiral ammonium salts and the tertiary intermediate in their syntheses transformation and we found that just small structural changes of the electrophile can be crucial whether ammonium salt formation is possible or not.

As already depicted above, the use of more rigid dihaloelectrophiles (e.g., xylene- or naphthyl-based ones) made quaternization possible (Scheme 3 ). We therefore attempted to introduce an axially chiral group by either reacting amines 5aa with dibromobiphenyl 17 or with both enantiomers of binaphthyl 18 (Scheme 5). In both cases the reaction proceeded quickly under the standard reaction conditions. The isolated ammonium salt 3aae was found to be a mixture of diastereomers containing additional impurities that could hardly be separated. In addition it was found that the amount of these impurities increased upon standing in solution and when the catalyst was exposed to basic conditions. Formation of both diastereomers of the binaphthyl-based salt 3aaf proceeded easily with full consumption of starting materials within a few hours. Crude NMR, TLC, and HRMS analyses confirmed the formation of the targeted product accompanied by significant amounts of by-products. Column chromatography allowed us to isolate the most polar spot (with $R_{f}$ values similar to those of other PTCs) solely. However, although ESI-HRMS proved the formation of the product, it was not possible to record a clean NMR spectrum of this compound as within minutes the formation of a much less polar product was observed (detected by TLC). Isolation of this compound (accompanied with other unidentified by-products) and analysis indicated the formation of the tertiary amine 19, ${ }^{23}$ most presumably via a Stevens type rearrangement, which is a well-known reaction for binaphthyl and biphenyl-based ammonium salts. ${ }^{24}$ Accordingly these highly crowded compounds turned out to be<smiles>CC(C)(C)OC1c2ccccc2CN(Cc2ccccc2-c2ccccc2)CC(c2ccccc2)(c2ccccc2)C2OC(C)(C)OC12</smiles><smiles>CC1(C)OC2C(C(CN3Cc4ccc5ccccc5c4-c4c(ccc5ccccc45)C3)(c3ccccc3)c3ccccc3)C(c3ccccc3)(c3ccccc3)C[C@H]2O1</smiles>

$(R)$ - or $(S)-18$

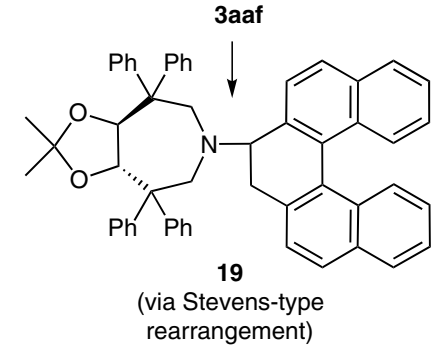

Scheme 5 Attempted syntheses of the centro-chiral-axially-chiral hybrid catalysts 3aae and 3aaf 
far too unstable to be used as chiral phase-transfer catalysts in asymmetric reactions (this behavior was even more pronounced in the case of amines bearing bulkier aryl groups).

It is worth noting that the quaternary ammonium salts $\mathbf{3}$ synthesized so far give rather broad ${ }^{1} \mathrm{H}$ NMR peaks $\left(\mathrm{CDCl}_{3}\right)$, especially for the $\mathrm{CH}_{2}$ groups adjacent to the quaternary ammonium group, thus indicating a certain conformational flexibility of the N-spiro skeleton. Accordingly, it seems that these ammonium salts are structurally less rigid than the axially chiral Maruoka catalysts.

Based on these investigations we were then able to synthesize a carefully investigated and extended library of acetonide containing catalysts $\mathbf{3 a}$ first and to identify the best-suited aryl substituents, quaternary ammonium group, and counter anion by testing these catalysts in the asymmetric $\alpha$-alkylation of glycine Schiff base $\mathbf{2 0}$ using benzyl bromide (21) as the electrophile. ${ }^{25}$ Table 1 gives a detailed overview on the acquired catalysts, the limitations of the developed synthesis route, and the results of the successfully obtained PTCs in the test reaction. After identifying the $p$-biphenyl-containing pyrrolidinium ammonium bromide 3aga as the most active amongst the tested acetonide-based catalysts (Table 1, entries 1-27) the influence of the ketal group on the catalytic potential of these PTCs was investigated next. Inspired by interesting results reported by the Shibasaki group about the influence of different ketal groups on the catalytic performance of their tartaric acid-derived two-center catalysts, ${ }^{6}$ we targeted a small library of $C_{1}$ - and $C_{2}$-symmetric catalysts based on the $p$-biphenyl azepane- $N$ pyrrolidinium skeleton with different ketal moieties (entries 28-35). With respect to the syntheses of these catalysts it was found necessary to start from the corresponding tartrates and bring them through the sequence, as we have so far not been able to carry out a selective transacetalization on one of the later stages. Interestingly, whereas different dialkyl ketals could easily be transferred through the developed sequence, the acetophenone-based catalyst 3 fga was not that easily obtained, as the dicyanation and reduction step were found to give an increased amount of difficult to separate impurities.

Testing the obtained ammonium salts in the asymmetric $\alpha$-alkylation of 20, a strong influence of the introduced ketal groups was observed. Amongst the $C_{2}$-symmetric catalysts the parent compound 3aga was found to be the most active one (Table 1, entry 8 vs. 28, 29). In the case of the $C_{1}$-symmetric ones, the tert-butyl containing catalyst 3ega (entry 31) was found to give by far the lowest selectivity. Interestingly, in contrast to the other catalysts this ammonium salt shows sharp NMR peaks, thus indicating that the tert-butyl holding group forces the rest of the skeleton in a more rigid (but less selective) conformation. Use of this catalyst in alternative solvents did not improve the result. Whereas the corresponding isobutyl and benzyl analogues (entries 30 and 33) performed slightly worse than 3aga, the acetophenone-based catalyst $\mathbf{3 f g a}$ gave $(S)-\mathbf{2 2}$ with the same enantioselectivity (entry 32 vs. 8). ${ }^{26}$ How- ever, as this compound was much more difficult to obtain than the others due to low yields and vast amounts of byproducts especially in the final steps we did not investigate it further. As most of the introduced substituents reduced the catalytic potential of our PTCs we also attempted to synthesize acetal-based catalysts. However, all attempts to obtain these ammonium salts (e.g., formaldehyde or benzaldehyde as the acetal group, entries 34 and 35) failed because the strong $\mathrm{LiAlH}_{4}$-reduction conditions always cleaved off these acetal groups. In addition, we also attempted to replace the dioxolane ring, for example, by a dioxane ring or by two methoxy groups. ${ }^{27}$ However, in both cases we were not able to prepare the corresponding dichlorides. Instead we observed formation of the corresponding tetrahydrofurans originating from an intramolecular nucleophilic substitution reaction on the monochloro intermediate.

Based on all these studies we finally identified the $p$-biphenyl-containing pyrrolidinium ammonium bromide 3aga as the most active catalyst for the asymmetric $\alpha$-alkylation of glycine Schiff base 20 (Table 1, entry 8). As recently disclosed, the use of different electrophiles in this reaction was well tolerated with up to $93 \%$ ee and isolated yields of $70-80 \%,{ }^{28}$ (for an overview, see Scheme 6, upper reaction scheme) thus making this compound a versatile catalyst for asymmetric reactions using prochiral nucleophiles. In addition the use of this catalyst was also investigated for the asymmetric epoxidation of chalcone 23, thus employing an achiral nucleophile and a prochiral electrophile (Scheme 6, lower reaction scheme). ${ }^{29}$ Unfortunately, despite a thorough screening of different reaction conditions it was not possible to obtain the epoxide $\mathbf{2 4}$ in any reasonable enantiomeric excess although the catalyst promoted the reaction well giving the product in high yield. $^{30}$

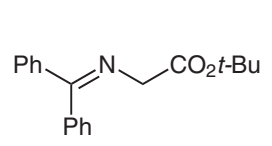

20

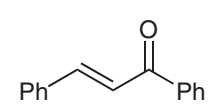

23
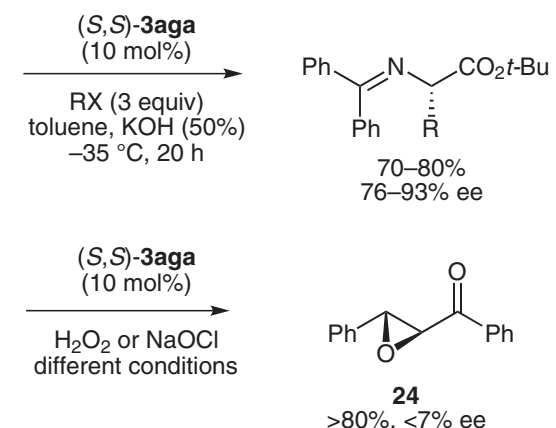

Scheme 6 Scope and limitation of TADDOL-derived PTC 3aga in asymmetric applications

\section{Azepane 5-Based Chiral Lewis Bases}

Chiral Lewis bases have proven to be useful catalysts for the activation of Lewis acids like, for example, organosilicon nucleophiles. We reasoned that the chiral secondary amines $\mathbf{5}$ present versatile starting materials to prepare chiral formamides 7 and chiral phosphoramides 9 . Where- 
Table 1 Targeted and Obtained Catalysts and Their Performance in the Asymmetric $\alpha$-Alkylation of Glycine Schiff Base 20

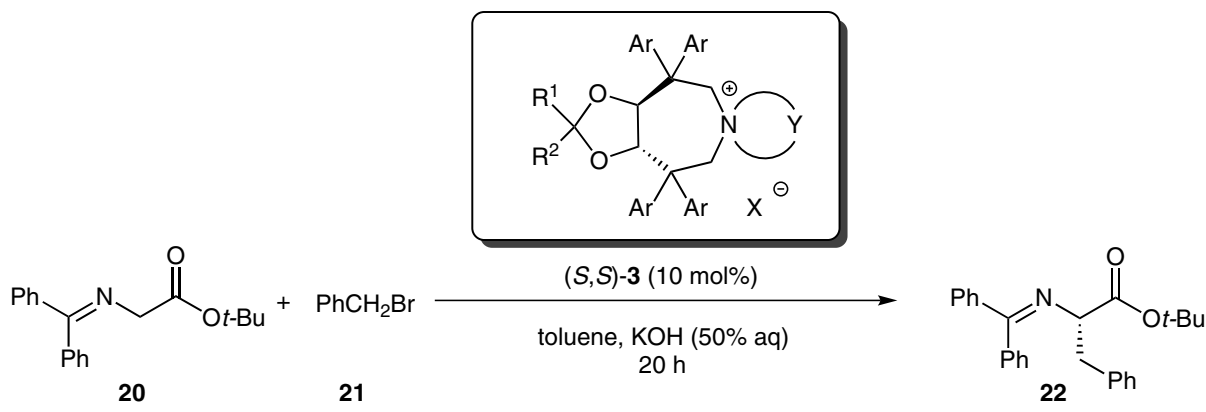

\begin{tabular}{|c|c|c|c|c|c|c|c|c|c|c|c|c|c|}
\hline \multirow[t]{2}{*}{ Entry } & \multirow[t]{2}{*}{$\mathrm{Cat}^{\mathrm{a}}$} & \multicolumn{4}{|l|}{ Catalyst structure } & \multicolumn{4}{|c|}{ Catalyst synthesis } & \multicolumn{4}{|l|}{ Alkylation } \\
\hline & & $\mathrm{Ar}$ & $\mathrm{R}^{1 / \mathrm{R}^{2}}$ & $\mathrm{Y}$ & $\mathrm{X}^{-}$ & 13 & 15 & 5 & 3 & 21 (equiv) & $\begin{array}{l}\text { Temp } \\
\left({ }^{\circ} \mathrm{C}\right)\end{array}$ & $\begin{array}{l}\text { Yield }^{\mathrm{c}}(\text { Conv. })^{\mathrm{d}} \\
(\%)\end{array}$ & $\begin{array}{l}\text { ee }(\%)^{\mathrm{e}} \\
(\text { Conf. })^{\mathrm{f}}\end{array}$ \\
\hline 1 & 3aaa & $\mathrm{Ph}$ & $\mathrm{Me} / \mathrm{Me}$ & $\mathbf{a}^{\mathrm{g}}$ & $\mathrm{Br}^{-}$ & + & + & + & + & 1.2 & -20 & $55(\sim 70)$ & $45(S)$ \\
\hline 2 & 3aba & $4-t-\mathrm{BuC}_{6} \mathrm{H}_{4}$ & & & & + & + & + & + & & & $30(\sim 50)$ & $61(S)$ \\
\hline 3 & 3aca & $4-\mathrm{FC}_{6} \mathrm{H}_{4}$ & & & & + & + & + & + & & & $35(\sim 50)$ & $34(S)$ \\
\hline 4 & 3ada & $3-\mathrm{MeC}_{6} \mathrm{H}_{4}$ & & & & + & + & + & + & & & $77(\sim 90)$ & $55(S)$ \\
\hline 5 & 3aea & $3,5-\mathrm{Me}_{2} \mathrm{C}_{6} \mathrm{H}_{3}$ & & & & + & + & + & + & & & $47(\sim 60)$ & $5(S)$ \\
\hline 6 & 3afa & $3-\mathrm{PhC}_{6} \mathrm{H}_{4}$ & & & & + & + & + & + & & & $45(\sim 60)$ & $7(S)$ \\
\hline 7 & 3aga & 4- $\mathrm{PhC}_{6} \mathrm{H}_{4}$ & & & & + & + & + & + & & & $65(\sim 80)$ & $79(S)$ \\
\hline 8 & 3aga & $4-\mathrm{PhC}_{6} \mathrm{H}_{4}$ & Me/Me & $\mathbf{a}^{\mathrm{g}}$ & $\mathbf{B r}^{-}$ & + & + & + & + & 3 & -35 & 81 (quant) & $87(S)$ \\
\hline 9 & 3aha & 4- $\left(4-\mathrm{MeOC}_{6} \mathrm{H}_{4}\right) \mathrm{C}_{6} \mathrm{H}_{4}$ & & & & + & + & + & + & & & $72(\sim 95)$ & $76(S)$ \\
\hline 10 & 3aia & $4-\left(3-\mathrm{F}_{3} \mathrm{CC}_{6} \mathrm{H}_{4}\right) \mathrm{C}_{6} \mathrm{H}_{4}$ & & & & + & + & + & + & & & $65(\sim 80)$ & $80(S)$ \\
\hline 11 & 3aja & 4- $\left(2,4,6-\mathrm{Me}_{3} \mathrm{C}_{6} \mathrm{H}_{2}\right) \mathrm{C}_{6} \mathrm{H}_{4}$ & & & & + & + & + & + & & & $45(\sim 60)$ & $47(S)$ \\
\hline 12 & 3aka & 4-(naphth-2-yl) $\mathrm{C}_{6} \mathrm{H}_{4}$ & & & & - & & & & & & - & - \\
\hline 13 & 3ala & $4-\mathrm{F}_{3} \mathrm{CC}_{6} \mathrm{H}_{4}$ & & & & - & & & & & & - & - \\
\hline 14 & 3ama & $3-\mathrm{F}_{3} \mathrm{CC}_{6} \mathrm{H}_{4}$ & & & & - & & & & & & - & - \\
\hline 15 & 3ana & $3-\mathrm{MeOC}_{6} \mathrm{H}_{4}$ & & & & - & & & & & & - & - \\
\hline 16 & 3aoa & $4-\mathrm{MeOC}_{6} \mathrm{H}_{4}$ & & & & - & & & & & & - & - \\
\hline 17 & 3apa & naphth-2-yl & & & & + & - & & & & & - & - \\
\hline 18 & 3aga & $4-\mathrm{PhC}_{6} \mathrm{H}_{4}$ & & & $\mathrm{BF}_{4}^{-}$ & + & + & + & + & 1.2 & -20 & $67(\sim 80)$ & $77(S)$ \\
\hline 19 & 3aga & & & & $\mathrm{PF}_{6}^{-}$ & + & + & + & + & & & $61(\sim 80)$ & $20(S)$ \\
\hline 20 & 3agb & & & $\mathbf{b}^{\mathrm{g}}$ & $\mathrm{Br}^{-}$ & + & + & + & + & & & $57(\sim 80)$ & $51(S)$ \\
\hline 21 & 3agc & & & $\mathbf{c}^{\mathrm{g}}$ & & + & + & + & + & & & $21(\sim 30)$ & $25(R)$ \\
\hline 22 & 3aad & $\mathrm{Ph}$ & & $\mathbf{d}^{\mathrm{h}}$ & & + & + & + & - & & & - & - \\
\hline 23 & 3agd & 4- $\mathrm{PhC}_{6} \mathrm{H}_{4}$ & & & & + & + & + & - & & & - & - \\
\hline 24 & 3aae & $\mathrm{Ph}$ & & $e^{i}$ & & + & + & + & - & & & - & - \\
\hline 25 & 3age & 4- $\mathrm{PhC}_{6} \mathrm{H}_{4}$ & & & & + & + & + & - & & & - & - \\
\hline 26 & 3aaf & $\mathrm{Ph}$ & & $\mathbf{f}^{i}$ & & + & + & + & - & & & - & - \\
\hline 27 & 3agf & $4-\mathrm{PhC}_{6} \mathrm{H}_{4}$ & & & & + & + & + & - & & & - & - \\
\hline 28 & 3bga & & $n-\mathrm{Bu} / n-\mathrm{Bu}$ & $\mathbf{a}^{\mathrm{g}}$ & & + & + & + & + & 3 & -35 & $73(\sim 95)$ & $78(S)$ \\
\hline 29 & $3 \operatorname{cga}$ & & $\left(\mathrm{CH}_{2}\right)_{5}$ & & & + & + & + & + & & & $69(\sim 90)$ & $82(S)$ \\
\hline 30 & 3dga & & $\mathrm{Me} / i-\mathrm{Bu}$ & & & + & + & + & + & & & $72(\sim 95)$ & $84(S)$ \\
\hline 31 & 3 ega & & $\mathrm{Me} / t-\mathrm{Bu}$ & & & + & + & + & + & & & 75 (quant) & $50(S)$ \\
\hline 32 & 3 fga & & $\mathrm{Me} / \mathrm{Ph}$ & & & + & + & + & + & & & $70(\sim 90)$ & $87(S)$ \\
\hline 33 & 3gga & & $\mathrm{Me} / \mathrm{Bn}$ & & & + & + & + & + & & & 79 (quant) & $80(S)$ \\
\hline 34 & 3hga & & $\mathrm{H} / \mathrm{H}$ & & & + & + & - & & & & - & - \\
\hline 35 & 3iga & & $\mathrm{H} / \mathrm{Ph}$ & & & + & + & - & & & & - & - \\
\hline
\end{tabular}

${ }^{a}$ The first alphabet denotes the ketal group, the second the aryl group, and the third the quaternary ammonium group.

${ }^{\mathrm{b}}$ The sign + or - indicates whether formation of the respective product was possible or not.

${ }^{\mathrm{c}}$ Isolated yields.

d Judged by NMR of the crude product.

${ }^{\mathrm{e}}$ Determined by HPLC using a chiral stationary phase.

${ }^{\mathrm{f}}$ Absolute configuration was determined by comparison of the HPLC retention time and optical rotation with literature values. ${ }^{22 \mathrm{~h}, 31}$

g See Scheme 3.

${ }^{\mathrm{h}}$ See Figure 1, compound 3aad.

${ }^{i}$ See Scheme 5, compounds 3aae and 3aaf. 
as synthesis of 7aa was easily accomplished by the reaction of $5 \mathbf{a a}\left(\mathrm{Ar}=\mathrm{Ph}, \mathrm{R}^{1}=\mathrm{R}^{2}=\mathrm{Me}\right)$ with acetic formic anhydride ( $88 \%$ yield), synthesis of 9aa turned out to be rather difficult. Although reaction of 5aa with $\mathrm{PCl}_{3}$ or $\mathrm{POCl}_{3}$ proceeded smoothly, further reaction with (di)amines was found to be problematic, especially due to the observed good leaving group ability of 5aa, which often resulted in the hydrolysis or $\mathrm{P}-\mathrm{N}$ bond cleavage of the intermediates. Direct reaction with $\mathrm{POCl}\left(\mathrm{NR}_{2}\right)_{2}$ was also not possible. However, after some optimization, it was found that a two-step reaction of $\mathbf{5 a a}$ with $\mathrm{POCl}_{3}$ first and immediate reaction with $N, N^{\prime}$-dimethylethylenediamine was possible to obtain the phosphoramide 9aa in $86 \%$ yield (Scheme 7). Interestingly, this compound tends to partially hydrolyze upon standing in solution (e.g., 3 days in aqueous $\mathrm{MeOH}$ ). To test these compounds for their catalytic potential the allylation of benzaldehyde (25) with trichloroallylsilane (26) was chosen as a benchmark reaction. Unfortunately, the homoallylic alcohol 27 was never obtained in reasonable yield, even when stoichiometric amounts of Lewis base activator were used, only racemic product could be obtained under a variety of different conditions with both activators (Scheme 7). ${ }^{32}$
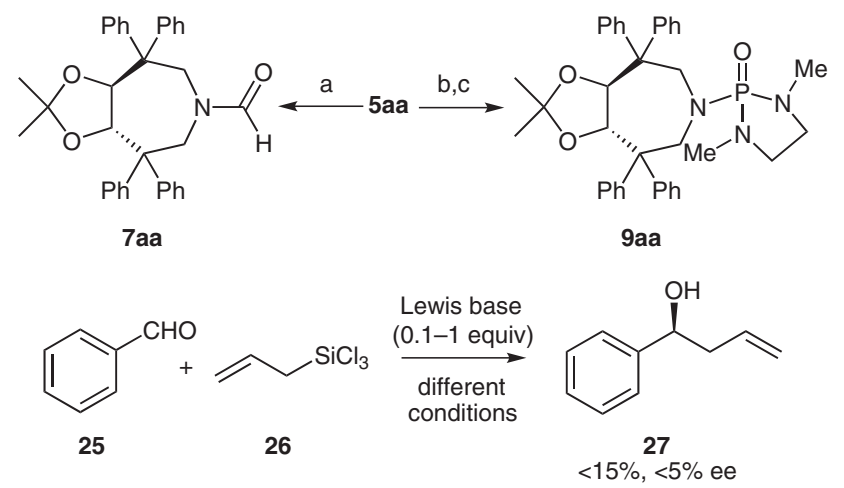

Scheme 7 Syntheses of chiral TADDOL-derived Lewis bases and attempted application: Reagents and conditions: a) acetic formic anhydride, Hünig's base, $\mathrm{CH}_{2} \mathrm{Cl}_{2}, 0-25^{\circ} \mathrm{C}, 88 \%$; b) $\mathrm{POCl}_{3}, \mathrm{KH}$, DMAP, $4 \AA \mathrm{MS}$, toluene, $60^{\circ} \mathrm{C}$; c) $N, N^{\prime}$-dimethylethylenediamine, $\mathrm{Et}_{3} \mathrm{~N}, \mathrm{CH}_{2} \mathrm{Cl}_{2}, 0-25^{\circ} \mathrm{C}, 86 \%$ (over two steps).

In conclusion, we have found that the literature known TADDOL-derived amine $\mathbf{4 a a}$ is not suitable as a starting material for the syntheses of novel PTCs or chiral Lewis bases due to a rather low reactivity of the nitrogen and an increased sensitivity of this compound under acidic and basic conditions. In contrast, the novel azepane-based amines $\mathbf{5}$ could be successfully employed to synthesize both PTCs and Lewis bases. Whereas the Lewis bases $7 \mathbf{a a}$ and 9aa were found to be catalytically inactive in the chosen test reaction, the N-spiro PTCs 3 were found to be powerful catalysts for the asymmetric $\alpha$-alkylation of glycine Schiff base 20 (up to 93\% ee). Noteworthy, the developed synthesis route proved to be suitable for the synthesis of amines/catalysts containing electron-neutral aromatic residues mainly. Surprisingly, the final quaternization step was found to be possible with a limited num- ber of dihalo-electrophiles in an intramolecular fashion only, whereas sterically more demanding electrophiles or intermolecular approaches stalled at the tertiary amines. Further applications of the PTCs are currently investigated and will be reported in due course.

Melting points were measured on a Kofler melting point microscope (Reichert, Vienna). ${ }^{1} \mathrm{H}$ and ${ }^{13} \mathrm{C}$ NMR spectra were recorded on a Bruker Avance DRX $500 \mathrm{MHz}$ spectrometer, a Bruker Avance III $300 \mathrm{MHz}$ spectrometer, and on a Bruker Avance III $700 \mathrm{MHz}$ spectrometer with TCI cryoprobe. All NMR spectra were recorded at $298 \mathrm{~K}$ and referenced on the solvent peak. High-resolution mass spectra were obtained using an Agilent 6520 Q-TOF mass spectrometer with an ESI source and an Agilent G1607A coaxial sprayer. IR spectra were recorded on a Shimadzu IR Affinity-1 FT IR spectrometer. Optical rotations were recorded on a Perkin-Elmer Polarimeter Model 241 MC. HPLC was performed using a Dionex Summit HPLC system with a Chiralcel OD-H $(250 \times 4.6 \mathrm{~mm})$ chiral stationary phase. All chemicals were purchased from commercial suppliers and used without further purification unless otherwise stated. All reactions were performed under an argon atmosphere. Starting TADDOLs were synthesized according and in analogy to known methods..$^{2,9,33}$ Molecular modeling studies of the ground states were performed using the MMFF94 force field (Pcmodel) and on the B3LYP/6-31G level (Gaussian).

\section{Catalyst $(S, S)$-3aga}

Dicyanide 15ag: $\mathrm{SOCl}_{2}(5.65 \mathrm{~mL}, 77.9 \mathrm{mmol})$ was added to a solution of $2 \mathrm{ag}(12.01 \mathrm{~g}, 15.6 \mathrm{mmol})$ in $\mathrm{CH}_{2} \mathrm{Cl}_{2}(280 \mathrm{~mL})$ and stirred at r.t. A solution of $\mathrm{Et}_{3} \mathrm{~N}(15.1 \mathrm{~mL}, 109 \mathrm{mmol})$ in $\mathrm{CH}_{2} \mathrm{Cl}_{2}(140 \mathrm{~mL})$ was added dropwise over $30 \mathrm{~min}$. The mixture was stirred for $1 \mathrm{~h}$ at r.t., cooled to $5{ }^{\circ} \mathrm{C}$ and sat. aq $\mathrm{NaHCO}_{3}(400 \mathrm{~mL})$ was added. The biphasic mixture was vigorously stirred for $90 \mathrm{~min}$, the layers were separated, the organic phase was dried $\left(\mathrm{Na}_{2} \mathrm{SO}_{4}\right)$, and evaporated to dryness. Crude 13ag formed was directly dissolved in $\mathrm{CH}_{2} \mathrm{Cl}_{2}(400$ $\mathrm{mL})$, cooled to $5{ }^{\circ} \mathrm{C}$ and TMSCN $(9.73 \mathrm{~mL}, 77.8 \mathrm{mmol})$ and $\mathrm{SnCl}_{4}$ $(1.82 \mathrm{~mL}, 15.6 \mathrm{mmol})$ were added. The mixture was warmed to r.t. over $1 \mathrm{~h}$ and stirred for $12 \mathrm{~h}$. After quenching with sat. aq $\mathrm{K}_{2} \mathrm{CO}_{3}$ $(200 \mathrm{~mL})$, the phases were separated, and the organic phase washed with sat. aq $\mathrm{K}_{2} \mathrm{CO}_{3}(2 \times 200 \mathrm{~mL})$ and brine $(2 \times 200 \mathrm{~mL})(\boldsymbol{C A U}$ TION! Aqueous phases contain residual cyanide!). After drying $\left(\mathrm{Na}_{2} \mathrm{SO}_{4}\right)$ and evaporation to dryness, the product was purified by column chromatography (heptanes-EtOAc, 5:1) to give dicyanide 15ag in $59 \%(7.26 \mathrm{~g}, 9.2 \mathrm{mmol})$ as a light brown solid; $\mathrm{mp}>220{ }^{\circ} \mathrm{C}$ (dec.); $[\alpha]_{\mathrm{D}}{ }^{20}+104.6\left(c 1.6, \mathrm{CHCl}_{3}\right)$.

IR (film): 3055, 3030, 1485, 1409, 1373, 1234, 1159, 1076, 1006, $835,742,694 \mathrm{~cm}^{-1}$.

${ }^{1} \mathrm{H}$ NMR $\left(500 \mathrm{MHz}, \mathrm{CDCl}_{3}\right): \delta=1.65(\mathrm{~s}, 6 \mathrm{H}), 5.68(\mathrm{~s}, 2 \mathrm{H}), 7.24$ $7.36(\mathrm{~m}, 14 \mathrm{H}), 7.39(\mathrm{~d}, J=8.4 \mathrm{~Hz}, 4 \mathrm{H}), 7.43(\mathrm{t}, J=7.6 \mathrm{~Hz}, 2 \mathrm{H})$, $7.52(\mathrm{t}, J=7.3 \mathrm{~Hz}, 4 \mathrm{H}), 7.65(\mathrm{~d}, J=8.8 \mathrm{~Hz}, 8 \mathrm{H}), 7.63(\mathrm{~d}, J=7.8$ $\mathrm{Hz}, 4 \mathrm{H})$.

${ }^{13} \mathrm{C}$ NMR $\left(125 \mathrm{MHz}, \mathrm{CDCl}_{3}\right): \delta=28.0\left(\mathrm{CH}_{3}\right), 56.6(\mathrm{CCN}), 81.9$ $(\mathrm{CH}), 111.2\left(\mathrm{CO}_{2}\right), 120.8(\mathrm{CN}), 126.9(\mathrm{ArC}), 127.1$ ( $\left.\mathrm{ArC}\right), 127.2$ (ArC), $127.4(\mathrm{ArC}), 127.5$ (ArC), 127.6 (ArC), 127.7 (ArC), 128.8 (ArC), 128.9 (ArC), 135.0 (ArC), 138.4 (ArC), 139.5 (ArC), 140.1 (ArC), 140.6 (ArC), 140.7 (ArC).

HRMS (ESI): $m / z$ calcd for $\mathrm{C}_{57} \mathrm{H}_{44} \mathrm{~N}_{2} \mathrm{O}_{2}: 806.3741\left[\mathrm{M}+\mathrm{NH}_{4}\right]^{+}$; found: 806.3751 .

Amine 5ag: A mixture of $\mathbf{1 5 a g}(2.13 \mathrm{~g}, 2.7 \mathrm{mmol})$ and $\mathrm{LiAlH}_{4}(2.05$ $\mathrm{g}, 54 \mathrm{mmol})$ in mesitylene $(100 \mathrm{~mL})$ was refluxed for $30-45 \mathrm{~min}$, cooled in an ice bath, and carefully quenched with EtOAc $(200 \mathrm{~mL})$ first, followed by the addition of $\mathrm{H}_{2} \mathrm{O}(150 \mathrm{~mL})$. After phase separation, the aqueous phase was extracted with EtOAc $(2 \times 150 \mathrm{~mL})$ and the combined organic layers were washed with brine $(3 \times 150$ $\mathrm{mL}$ ). After drying $\left(\mathrm{Na}_{2} \mathrm{SO}_{4}\right)$ and evaporation to dryness, the product was purified by column chromatography (heptanes-EtOAc, 5:1) to 
give $\mathbf{5 a g}(631 \mathrm{mg}, 30 \%, 0.81 \mathrm{mmol})$ as a white foam; $[\alpha]_{\mathrm{D}}{ }^{20}-143.4$ (c 1.14, $\mathrm{CHCl}_{3}$ ).

IR (film): 3028, 2983, 1732, 1598, 1485, 1369, 1240, 1215, 1166, $1072,1006,831,763,742 \mathrm{~cm}^{-1}$.

${ }^{1} \mathrm{H} \mathrm{NMR}\left(500 \mathrm{MHz}, \mathrm{CDCl}_{3}\right): \delta=0.86(\mathrm{~s}, 6 \mathrm{H}), 3.54(\mathrm{~d}, J=14.5 \mathrm{~Hz}$, $2 \mathrm{H}), 3.89(\mathrm{~d}, J=14.5 \mathrm{~Hz}, 2 \mathrm{H}), 5.21(\mathrm{~s}, 2 \mathrm{H}), 7.31-7.34(\mathrm{~m}, 4 \mathrm{H})$, 7.41-7.44 (m, $12 \mathrm{H}), 7.51-7.64(\mathrm{~m}, 20 \mathrm{H})$.

${ }^{13} \mathrm{C}$ NMR $\left(125 \mathrm{MHz}, \mathrm{CDCl}_{3}\right): \delta=27.0\left(\mathrm{CH}_{3}\right), 53.7\left(\mathrm{Ar}_{2} \mathrm{C}\right), 63.1$ $\left(\mathrm{CH}_{2} \mathrm{~N}\right), 79.7(\mathrm{CH}), 109.6\left(\mathrm{CO}_{2}\right), 125.7(\mathrm{ArC}), 126.9(\mathrm{ArC}), 127.1$ (ArC), 127.2 (ArC), 127.3 (ArC), 127.4 (ArC), $128.8(\mathrm{ArC}), 128.9$ (ArC), 131.7 (ArC), 139.0 (ArC), 139.1 (ArC), 140.9 (ArC), 141.0 (ArC), 142.8 (ArC), $147.6(\mathrm{ArC})$.

HRMS (ESI): $m / z$ calcd for $\mathrm{C}_{57} \mathrm{H}_{49} \mathrm{NO}_{2}: 818.3395[\mathrm{M}+\mathrm{K}]^{+}$; found: 818.3376

Catalyst 3aga: A mixture of 5 ag (134 mg, $0.172 \mathrm{mmol})$, 1,4-dibromobutane $(81 \mu \mathrm{L}, 0.689 \mathrm{mmol})$, and $\mathrm{K}_{2} \mathrm{CO}_{3}(95 \mathrm{mg}, 0.689 \mathrm{mmol})$ in $\mathrm{MeCN}(10 \mathrm{~mL})$ was refluxed for 2 days. The inorganic salts were filtered off, the solvent evaporated, and the residue purified by column chromatography $\left(\mathrm{CH}_{2} \mathrm{Cl}_{2}-\mathrm{MeOH}, 10: 1\right)$ to obtain ammonium salt 3aga as a white solid (108 mg, 57\%, $0.118 \mathrm{mmol})$; mp 163 $168^{\circ} \mathrm{C} ;[\alpha]_{\mathrm{D}}^{20}-57.4\left(c 0.74, \mathrm{CHCl}_{3}\right)$.

IR (film): 3028, 2931, 1736, 1487, 1371, 1247, 1213, 1161, 1078, $1006,837,765,740,696 \mathrm{~cm}^{-1}$.

${ }^{1} \mathrm{H} \mathrm{NMR}\left(500 \mathrm{MHz}, \mathrm{CDCl}_{3}\right): \delta=0.89(\mathrm{~s}, 6 \mathrm{H}), 1.24(\mathrm{br}, 2 \mathrm{H}), 1.62$ (br, $2 \mathrm{H}), 3.57$ (br m, 2 H), 3.77 (br m, $2 \mathrm{H}), 5.03$ (br m, $2 \mathrm{H}$ ), 5.44 (br m, $2 \mathrm{H}), 5.64$ (s, $2 \mathrm{H}), 7.31-7.41(\mathrm{~m}, 8 \mathrm{H}), 7.46$ (t, $J=7.2 \mathrm{~Hz}, 4$ H), 7.52-7.62 (m, $12 \mathrm{H}), 7.67(\mathrm{~d}, J=7.8 \mathrm{~Hz}, 4 \mathrm{H}), 7.74(\mathrm{~d}, J=7.5$ $\mathrm{Hz}, 4 \mathrm{H}), 7.97$ (br s, $4 \mathrm{H}$ ).

${ }^{13} \mathrm{C}$ NMR $\left(125 \mathrm{MHz}, \mathrm{CDCl}_{3}\right): \delta=20.7\left(\mathrm{CH}_{2}\right), 25.8\left(\mathrm{CH}_{3}\right), 52.6$ $\left(\mathrm{Ar}_{2} \mathrm{C}\right), 66.8\left(\mathrm{CH}_{2} \mathrm{~N}^{+}\right), 70.6\left(\mathrm{CH}_{2} \mathrm{~N}^{+}\right), 79.2(\mathrm{CH}), 110.9\left(\mathrm{CO}_{2}\right), 127.0$ $(2 \times \mathrm{ArC}), 127.1(\mathrm{ArC}), 127.5(\mathrm{ArC}), 127.7(\mathrm{ArC}), 127.8(\mathrm{ArC})$, $129.0(2 \times \mathrm{ArC}), 129.1$ (ArC), 131.3 (ArC), 138.1 (ArC), 139.9 (ArC), 140.0 (ArC), 140.1 (ArC), 140.3 (ArC), 143.6 (ArC).

HRMS (ESI): $m / z$ calcd for $\mathrm{C}_{61} \mathrm{H}_{56} \mathrm{NO}_{2}^{+}: 834.4306\left[\mathrm{M}^{+}\right]$; found: 834.4317.

Phase-Transfer Catalyzed $\alpha$-Alkylation of Glycine Schiff Base 20; General Procedure

A mixture of $20(0.2-1 \mathrm{mmol})$ and catalyst 3aga $(10 \mathrm{~mol} \%)$ in toluene $(6.5 \mathrm{~mL} / \mathrm{mmol} \mathrm{20})$ was cooled to $0{ }^{\circ} \mathrm{C}$. Aq $50 \% \mathrm{KOH}(2$ $\mathrm{mL} / \mathrm{mmol} \mathrm{20}$ ) was added and the vigorously stirred mixture $(>1200$ $\mathrm{rpm}$ ) cooled to $-35^{\circ} \mathrm{C}$. After addition of the electrophile (3 equiv), the biphasic mixture was stirred for $20 \mathrm{~h}$ at $-35^{\circ} \mathrm{C}$. After extraction with $\mathrm{CH}_{2} \mathrm{Cl}_{2}(2 \times 15 \mathrm{~mL})$ and washing the combined extracts with $\mathrm{H}_{2} \mathrm{O}(5 \mathrm{~mL})$ and brine $(5 \mathrm{~mL})$, the combined organic phases were dried $\left(\mathrm{Na}_{2} \mathrm{SO}_{4}\right)$, evaporated to dryness, and purified by column chromatography. The alkylation products were isolated using heptanes-EtOAc (15:1) as eluent whereas the catalyst could be recovered in $>85 \%$ by flushing with $\mathrm{CH}_{2} \mathrm{Cl}_{2}-\mathrm{MeOH}(10: 1)$. The catalyst could be reused several times without any decrease in yield or enantioselectivity.

\section{Compound $(S)-22$}

Obtained in $81 \%$ yield and with $87 \%$ ee upon reacting 20 with benzyl bromide (21); colorless oil. Analytical data are in full accordance with those reported in the literature, ${ }^{22 \mathrm{~h}, 31}[\alpha]_{\mathrm{D}}{ }^{20}-125.7(c$ $\left.1.53, \mathrm{CHCl}_{3}\right)$.

${ }^{1} \mathrm{H}$ NMR $\left(300 \mathrm{MHz}, \mathrm{CDCl}_{3}\right): \delta=1.43(\mathrm{~s}, 9 \mathrm{H}), 3.11-3.23(\mathrm{~m}, 2 \mathrm{H})$, $4.10(\mathrm{dd}, J=9.0,4.2 \mathrm{~Hz}, 1 \mathrm{H}), 6.59(\mathrm{~d}, J=6.6 \mathrm{~Hz}, 2 \mathrm{H}), 7.03-7.40$ $(\mathrm{m}, 11 \mathrm{H}), 7.61(\mathrm{~d}, J=8.2 \mathrm{~Hz}, 2 \mathrm{H})$.

${ }^{13} \mathrm{C} \mathrm{NMR}\left(75 \mathrm{MHz}, \mathrm{CDCl}_{3}\right): \delta=28.0,39.6,68.0,81.2,126.2,127.7$, $127.9,128.0,128.1,128.3,128.8,129.9,130.1,136.4,138.4,139.6$, $170.3,170.9$.

HRMS (ESI): $m / z$ calcd for $\mathrm{C}_{26} \mathrm{H}_{27} \mathrm{NO}_{2}: 386.2115[\mathrm{M}+\mathrm{H}]^{+}$; found: 386.2113 .

\section{Formamide 7aa}

A solution of $5 \mathbf{a a}(123 \mathrm{mg}, 0.258 \mathrm{mmol})$ and Hünig's base $(88 \mu \mathrm{L}$, $0.516 \mathrm{mmol})$ in $\mathrm{CH}_{2} \mathrm{Cl}_{2}(6 \mathrm{~mL})$ was cooled to $0{ }^{\circ} \mathrm{C}$ and acetic formic anhydride $(38 \mu \mathrm{L}, 0.516 \mathrm{mmol})$ was added. The mixture was warmed to r.t. over $1 \mathrm{~h}$ and stirred for $2 \mathrm{~h}$. After washing with brine $(5 \mathrm{~mL})$, the organic layer was dried $\left(\mathrm{Na}_{2} \mathrm{SO}_{4}\right)$, and evaporated to dryness. The product was purified by column chromatography (heptanes-EtOAc, 1:1) to give formamide $7 \mathbf{a a}$ as a white foam $(115 \mathrm{mg}$, $88 \%, 0.228 \mathrm{mmol}) ;[\alpha]_{\mathrm{D}}{ }^{20}-247.5\left(\mathrm{c} 2.3, \mathrm{CHCl}_{3}\right)$.

${ }^{1} \mathrm{H}$ NMR (500 MHz, $\mathrm{CDCl}_{3}$ ): $\delta=0.51(\mathrm{~s}, 3 \mathrm{H}), 0.89$ (s, $\left.3 \mathrm{H}\right), 3.03$ $(\mathrm{d}, J=14.8 \mathrm{~Hz}, 1 \mathrm{H}), 4.28(\mathrm{~d}, J=15.0 \mathrm{~Hz}, 1 \mathrm{H}), 4.36(\mathrm{~d}, J=15.0$ $\mathrm{Hz}, 1 \mathrm{H}), 4.91(\mathrm{~d}, J=8.6 \mathrm{~Hz}, 1 \mathrm{H}), 5.18(\mathrm{~d}, J=14.8 \mathrm{~Hz}, 1 \mathrm{H}), 5.26$ $(\mathrm{d}, J=8.6 \mathrm{~Hz}, 1 \mathrm{H}), 7.20-7.35(\mathrm{~m}, 18 \mathrm{H}), 7.40-7.45(\mathrm{~m}, 2 \mathrm{H}), 7.54$ (s, $1 \mathrm{H})$.

${ }^{13} \mathrm{C}$ NMR $\left(125 \mathrm{MHz}, \mathrm{CDCl}_{3}\right): \delta=26.1\left(\mathrm{CH}_{3}\right), 27.2\left(\mathrm{CH}_{3}\right), 52.9$ $\left(\mathrm{Ar}_{2} \mathrm{C}\right), 54.9\left(\mathrm{Ar}_{2} \mathrm{C}\right), 55.4\left(\mathrm{CH}_{2} \mathrm{~N}\right), 59.1\left(\mathrm{CH}_{2} \mathrm{~N}\right), 77.9(\mathrm{CH}), 78.5$ $(\mathrm{CH}), 110.6\left(\mathrm{CO}_{2}\right), 126.1$ (ArC), 126.4 (ArC), 126.5 (ArC), 126.6 $(2 \times \mathrm{ArC}), 127.0(\mathrm{ArC}), 127.5(\mathrm{ArC}), 127.8(\mathrm{ArC}), 128.1(2 \times \mathrm{ArC})$, 129.9 (ArC), 130.8 (ArC), 141.2 (ArC), 141.7 (ArC), 145.8 (ArC), 146.8 (ArC), 163.9 (NCHO).

HRMS (ESI): $m / z$ calcd for $\mathrm{C}_{34} \mathrm{H}_{33} \mathrm{NO}_{3}: 504.2533[\mathrm{M}+\mathrm{H}]^{+}$; found: 504.2543 .

\section{Phosphoramide 9aa}

A mixture of 5aa $(52 \mathrm{mg}, 0.109 \mathrm{mmol}), \mathrm{KH}(17 \mathrm{mg}, 0.424 \mathrm{mmol})$, DMAP (13 mg, $0.106 \mathrm{mmol})$, and activated $4 \AA$ molecular sieves $(50 \mathrm{mg})$ in anhyd toluene $(4 \mathrm{~mL})$ was cooled to $0{ }^{\circ} \mathrm{C}$ and a solution of $\mathrm{POCl}_{3}(40 \mu \mathrm{L}, 0.429 \mathrm{mmol})$ in anhyd toluene $(1 \mathrm{~mL})$ was added dropwise over $30 \mathrm{~min}$. The mixture was warmed to $60^{\circ} \mathrm{C}$ over $1 \mathrm{~h}$ and stirred at this temperature for $40 \mathrm{~h}$. After filtration over a pad of Celite, the solvent was evaporated and the residue dissolved in anhyd $\mathrm{CH}_{2} \mathrm{Cl}_{2}(3 \mathrm{~mL})$, followed by the addition of $\mathrm{Et}_{3} \mathrm{~N}(58 \mu \mathrm{L}, 0.418$ $\mathrm{mmol}$ ) and cooling to $-10{ }^{\circ} \mathrm{C}$. After dropwise addition of a solution of $N, N^{\prime}$-dimethylethylenediamine $(23 \mu \mathrm{L}, 0.212 \mathrm{mmol})$ in anhyd $\mathrm{CH}_{2} \mathrm{Cl}_{2}(1 \mathrm{~mL})$, the mixture was allowed to warm up to r.t. over $2 \mathrm{~h}$, and stirred for $16 \mathrm{~h}$. The resulting mixture was evaporated to dryness and the residue was purified by column chromatography (EtOAc) to give phosphoramide 9aa (57 mg, 86\%, $0.094 \mathrm{mmol}$ ) as an oily residue (the compound tends to be sensitive to hydrolysis upon standing in solution); $[\alpha]_{\mathrm{D}}{ }^{20}-141.2\left(c 2.85, \mathrm{CHCl}_{3}\right)$.

${ }^{1} \mathrm{H} \mathrm{NMR}\left(500 \mathrm{MHz}, \mathrm{CDCl}_{3}\right): \delta=0.69(\mathrm{~s}, 6 \mathrm{H}), 1.74(\mathrm{~d}, J=9.7 \mathrm{~Hz}$, $3 \mathrm{H}), 2.49(\mathrm{~m}, 1 \mathrm{H}), 2.52(\mathrm{~d}, J=9.7 \mathrm{~Hz}, 3 \mathrm{H}), 2.84(\mathrm{~m}, 1 \mathrm{H}), 3.07$ $(\mathrm{m}, 2 \mathrm{H}), 3.60(\mathrm{dd}, J=14.8,8.3 \mathrm{~Hz}, 2 \mathrm{H}), 4.58(\mathrm{dd}, J=14.8,8.3$ $\mathrm{Hz}, 2 \mathrm{H}), 5.10$ (s, $2 \mathrm{H}), 7.16-7.34$ (m, $16 \mathrm{H}), 7.52-7.58$ (m, $4 \mathrm{H})$.

${ }^{13} \mathrm{C}$ NMR $\left(125 \mathrm{MHz}, \mathrm{CDCl}_{3}\right): \delta=26.8\left(\mathrm{CH}_{3}\right), 30.2(\mathrm{~d}, J=4 \mathrm{~Hz}$, $\left.\mathrm{CH}_{3}\right), 31.3\left(\mathrm{~d}, J=5 \mathrm{~Hz}, \mathrm{CH}_{3}\right), 46.1\left(\mathrm{~d}, J=13 \mathrm{~Hz}, \mathrm{CH}_{2}\right), 48.2$ (d, $\left.J=11 \mathrm{~Hz}, \mathrm{CH}_{2}\right), 53.8\left(\mathrm{Ar}_{2} \mathrm{C}\right), 53.9\left(\mathrm{Ar}_{2} \mathrm{C}\right), 61.5\left(\mathrm{CH}_{2} \mathrm{~N}\right), 78.5(\mathrm{CH})$, $109.9\left(\mathrm{CO}_{2}\right), 126.2(\mathrm{ArC}), 126.6(\mathrm{ArC}), 121.1(\mathrm{ArC}), 128.1(\mathrm{ArC})$, 128.9 (ArC), 131.6 (ArC), 142.7 (ArC), 148.0 (ArC).

${ }^{31} \mathrm{P}$ NMR $\left(81 \mathrm{MHz}, \mathrm{CDCl}_{3}\right): \delta=31.6$.

HRMS (ESI): $m / z$ calcd for $\mathrm{C}_{37} \mathrm{H}_{42} \mathrm{~N}_{3} \mathrm{O}_{3} \mathrm{P}: 608.3037[\mathrm{M}+\mathrm{H}]^{+}$; found: 608.3044 .

\section{Acknowledgment}

This work was supported by the Austrian Science Funds (FWF): Project No. P22508-N17. We are grateful to Dr. Manuela Haunschmidt and Dr. Markus Himmelsbach for their support with HRMS analysis and to Christian Rückl for his help with the HPLC analysis. We are grateful to Dr. Christoph Etzlstorfer for assisting with the molecular modeling studies. The used NMR spectrometers were acquired in collaboration with the University of South Bohemia (CZ) with financial support from the European Union through the EFRE INTERREG IV ETC-AT-CZ program (project M00146, 'RERI-uasb'). 
Supporting Information for this article is available online at http://www.thieme-connect.com/ejournals/toc/synthesis. Included are analytical data of catalyst analogues, precursors, alkylation products, and copies of NMR spectra, HPLC chromatograms, and Tables with details of optimization and scope of the PT-catalyzed $\alpha$-alkylation .

\section{References}

(1) For comprehensive overviews about organocatalysis, see: (a) Berkessel, A.; Gröger, H. Asymmetric Organocatalysis: From Biomimetic Concepts to Applications in Asymmetric Synthesis; Wiley-VCH: Weinheim, 2005. (b) Dalko, I. Enantioselective Organocatalysis; Wiley-VCH: Weinheim, 2007. (c) Waser, M. In Progress in the Chemistry of Organic Natural Products; Vol. 96; Kinghorn, A.-D.; Falk, H.; Kobayashi, J., Eds.; Springer: Berlin, 2012.

(2) For reviews on TADDOLs, see: (a) Seebach, D.; Beck, A. K.; Heckel, A. Angew. Chem. Int. Ed. 2001, 40, 92. (b) Pellissier, H. Tetrahedron 2008, 64, 10279.

(3) For a recent report describing the syntheses of tartaric acid derived 1,4-ditertiary carbinols, see: Budragchaa, T.; Roller, A.; Widhalm, M. Synthesis 2012, 44, 3238.

(4) For the application of TADDOLs and derived organocatalysts as chiral H-bonding donors or Brønstedt acids, see: (a) Huang, Y.; Unni, A. K.; Thadani, A. N.; Rawal, V. H. Nature 2003, 424, 146. (b) McGilvra, J. D.; Unni, A. K.; Modi, K.; Rawal, V. H. Angew. Chem. Int. Ed. 2006, 45, 6130. (c) Akiyama, T.; Saitoh, Y.; Morita, H.; Fuchibe, K. Adv. Synth. Catal. 2008, 347, 1523. (d) Lauber, M.; Fröhlich, R.; Paradies, J. Synthesis 2012, 44, 3209. (e) Seebach, D.; Beck, A. K.; Bichsel, H.-U.; Pichota, A.; Sparr, C.; Wünsch, R.; Schweizer, W. B. Helv. Chim. Acta 2012, 95, 1303.

(5) For TADDOLs as PTCs, see: (a) Belokon, Y. N.; Kochetkov, K. A.; Churkina, T. D.; Ikonnikov, N. S.; Chesnokov, A. A.; Larionov, O. V.; Singh, I.; Parmar, V. S.; Vyskocil, S.; Kagan, H. B. J. Org. Chem. 2000, 65, 7041. (b) Belokon, Y. N.; Kochetkov, K. A.; Churkina, T. D.; Ikonnikov, N. S.; Chesnokov, A. A.; Larionov, O. V.; Parmar, V. S.; Kumar, R.; Kagan, H. B. Tetrahedron: Asymmetry 1998, 9, 851.

(6) For tartaric acid derived PTCs, see: (a) Shibuguchi, T.; Fukuta, Y.; Akachi, Y.; Sekine, A.; Ohshima, T.; Shibasaki, M. Tetrahedron Lett. 2002, 43, 9539. (b) Ohshima, T.; Gnanadesikan, V.; Shibuguchi, T.; Fukuta, Y.; Nemoto, T.; Shibasaki, M. J. Am. Chem. Soc. 2003, 125, 11206.

(c) Ohshima, T.; Shibuguchi, T.; Fukuta, Y.; Shibasaki, M. Tetrahedron 2004, 60, 7743. (d) Okada, A.; Shibuguchi, T.; Ohshima, T.; Masu, H.; Yamaguchi, K.; Shibasaki, M. Angew. Chem. Int. Ed. 2005, 44, 4564. (e) Shibuguchi, T.; Mihara, H.; Kuramochi, A.; Ohshima, T.; Shibasaki, M. Chem.-Asian. J. 2007, 2, 794.

(7) Waser, M.; Haunschmidt, M.; Himmelsbach, M. Monatsh. Chem. 2010, 141, 1347.

(8) Waser, M.; Gratzer, K.; Herchl, R.; Müller, N. Org. Biomol. Chem. 2012, 10, 251

(9) (a) Seebach, D.; Beck, A. K.; Hayakawa, M.; Jaeschke, G.; Kühnle, F. N. M.; Nageli, I.; Pinkerton, A. B.; Rheiner, P. B.; Duthaler, R. O.; Rothe, P. M.; Weigand, W.; Wünsch, R.; Dick, S.; Nesper, R.; Wörle, M.; Gramlich, V. Bull. Soc. Chim. Fr. 1997, 134, 315. (b) Seebach, D.; Hayakawa, M.; Sakaki, J.; Schweizer, W. B. Tetrahedron 1993, 49, 1711. (c) Beck, A. K.; Bastani, B.; Plattner, D. A.; Petter, W.; Seebach, D.; Braunschweiger, H.; Gysi, P.; Lavecchia, L. Chimia 1991, 45, 238. (d) Pichota, A.; Gramlich, V.; Beck, A. K.; Seebach, D. Helv. Chim. Acta 2012, 95, 1239. (e) Pichota, A.; Gramlich, V.; Bichsel, H.-U.; Styner, T.; Knöpfel, T.; Wünsch, R.; Hintermann, T.; Schweizer, W. B.; Beck, A. K.; Seebach, D. Helv. Chim. Acta 2012, 95, 1273.

(10) For reviews on chiral Lewis base catalysis, see:

(a) Denmark, S. E.; Beutner, G. L. Angew. Chem. Int. Ed. 2008, 47, 1560. (b) Denmark, S. E.; Stavenger, R. A. Acc. Chem. Res. 2000, 33, 432.

(11) For reviews about asymmetric phase-transfer catalysis, see: (a) Maruoka, K. Asymmetric Phase Transfer Catalysis; Wiley-VCH: Weinheim, 2008. (b) Maruoka, K.; Ooi, T. Chem. Rev. 2003, 103, 3013. (c) O'Donnell, M. J. Acc. Chem. Res. 2004, 37, 506. (d) Lygo, B.; Andrews, B. I. Acc. Chem. Res. 2004, 37, 518. (e) Hashimoto, T.; Maruoka, K. Chem. Rev. 2007, 107, 5656. (f) Ooi, T.; Maruoka, K. Angew. Chem. Int. Ed. 2007, 46, 4222.

(12) Weibel, D. Ph.D. Dissertation; ETH: Zürich, 2003, Nr. 1529.

(13) Due to the failed syntheses of catalysts $6, \mathbf{1 0}$, and $\mathbf{1 2}$, the synthesis of phosphoramides $\mathbf{8}$ was not exhaustively investigated anymore after the failure of a few initial experiments.

(14) Seebach et al. coincidentally observed the formation of trityl derivatives upon treatment of dichloro compound $\mathbf{1 3}$ with diphenylamine or methylaniline: Seebach, D.; Pichota, A.; Beck, A. K.; Pinkerton, A. B.; Litz, T.; Karjalainen, J.; Gramlich, V. Org. Lett. 1999, 1, 55.

(15) Reetz, M. T.; Chatzhosifidis, I.; Künzer, H.; Müller-Starke, H. Tetrahedron 1983, 39, 961 .

(16) $\mathrm{BH}_{3} \cdot \mathrm{DMS}$ in refluxing THF was the only other reducing agent that gave small amounts of 5 aa $(? 20 \%)$.

(17) $p$-Methoxy-substituted TADDOL gave elimination and Friedel-Crafts products in the chlorination step exclusively, whereas the $m$-methoxy one gave at least small amounts of the dichlorides, which then formed only Friedel-Crafts products, but not dinitrile under the Lewis acidic cyanation conditions.

(18) Synthesis of the TADDOL 2aa based sulfite 16aa was reported by Seebach et al. in ref. $9 \mathrm{~b}$.

(19) In these two cases it was necessary to use 5 equiv of TMSCN and 1 equiv $\mathrm{SnCl}_{4}$ to obtain the dicyanides in a reliable and reproducible manner.

(20) Using MeI, trace amounts of the targeted ammonium iodide could be detected by ESI-HRMS of the crude reaction mixture, but no product could be isolated.

(21) For detailed investigations concerning the kinetics of $\mathrm{S}_{\mathrm{N}} 2-$ type cyclization reactions, see: (a) Freundlich, H.; Kroepelin, H. Z. Physik. Chem. 1926, 122, 39. (b) Casadei, M. A.; Galli, C.; Mandolini, L. J. Am. Chem. Soc. 1984, 106, 1051 .

(22) (a) Shirakawa, S.; Liu, K.; Ito, H.; Maruoka, K. Chem. Commun. 2011, 47, 1515. (b) Kano, T.; Yamamoto, A.; Song, S.; Maruoka, K. Chem. Commun. 2011, 47, 4358. (c) Shirakawa, S.; Terao, S. J.; He, R.; Maruoka, K. Chem. Commun. 2011, 47, 10557. (d) Hashimoto, T.; Sakata, K.; Maruoka, K. Adv. Synth. Catal. 2010, 352, 1653. (e) Lan, Q.; Wang, X.; Shirakawa, S.; Maruoka, K. Org. Process Res. Dev. 2010, 14, 684. (f) Ooi, T.; Kameda, M.; Maruoka, K. J. Am. Chem. Soc. 2003, 125, 5139. (g) Shirakawa, S.; Liu, K.; Maruoka, K. J. Am. Chem. Soc. 2012, 134, 916. (h) Ooi, T.; Kameda, M.; Maruoka, K. J. Am. Chem. Soc. 1999, 121, 6519.

(23) This compound was not unambiguously proven by NMR analysis due to the presence of other by-products (maybe also due to the presence of other possible Stevens rearrangement products), but could be clearly identified by HRMS in the positive ion mode. 
(24) Goncalves-Farbos, M.-H.; Vial, L.; Lacour, J. Chem. Commun. 2008, 829.

(25) For optimization of the reaction conditions and catalyst amount, please see the detailed tables in the Supporting Information and the preliminary results in our recent communication (ref. 8).

(26) We have also synthesized the corresponding 2-acetylnaphthalene-based derivative, which performed slightly better ( $88 \%$ ee in the benchmark alkylation), but was even harder to obtain as the last steps were significantly lower yielding and vast amounts of difficult to remove impurities were formed.

(27) For successful applications of acyclic TADDOL-backbone containing ligands in asymmetric catalysis, see: (a) Teller, H.; Flügge, S.; Goddard, R.; Fürstner, A. Angew. Chem. Int. Ed. 2010, 122, 1993. (b) Teller, H.; Fürstner, A. Chem.-Eur. J. 2011, 17, 7764 .
(28) For detailed scope, see the tables in the Supporting Information and the preliminary results in our recent communication (ref. 8).

(29) For a recent example using cinchona-based PTCs, see: Yoo, M. S.; Kim, D. G.; Ha, M. W.; Jew, S.; Park, H.; Jeong, B. S. Tetrahedron Lett. 2010, 51, 5601.

(30) No background reaction was observed in the absence of the catalyst.

(31) Corey, E. J.; Xu, F.; Noe, M. C. J. Am. Chem. Soc. 1997, $119,12414$.

(32) Also the use of more reactive $p$-nitrobenzaldehyde did not result in a better conversion.

(33) (a) Weber, E.; Dörpinghaus, N.; Wimmer, C.; Stein, Z.; Krupitsky, H.; Goldberg, I. J. Org. Chem. 1992, 57, 6825. (b) Voituriez, A.; Charette, A. B. Adv. Synth. Catal. 2006, 348, 2363. (c) Kelly, T. R.; Cai, X.; Elliott, E. L.; Grossmann, G.; Laurent, P. Org. Lett. 2004, 6, 4953. 